\title{
Percutaneous Coronary Intervention in Elderly: It is Never Too Late!
}

\author{
Y. Sathyanarayana Raju ${ }^{1}$ \\ ${ }^{1}$ Department of General Medicine, Nizam's Institute of Medical \\ Sciences, Panjagutta, Hyderabad, Telangana, India
}

Ind J Car Dis Wom 2020;5:25-26

Globally, the population is increasing. As per the estimates of the World Health Organization (WHO), the proportion of the population aged over 60 years will double from $11 \%$ in 2002 to $22 \%$ by $2050 .{ }^{1}$ By the year 2021 , it is estimated that the proportion of over 60 years population is expected to increase to $10.7 \%$ in India. ${ }^{2,3}$ Thus, keeping pace with the increase in world population, the proportion of elderly population is also increasing globally. Consequent to increase in the life expectancy with increasing aging, a significant increase in the burden of noncommunicable diseases, coronary artery disease (CAD) is also increasing. CAD has emerged as a major cause of morbidity and mortality in elderly subjects. ${ }^{4}$ It is common in present-day clinical practice to encounter an increasing number of elderly people who present with chronic stable angina and acute coronary syndrome and who require coronary revascularization, either by coronary artery bypass grafting (CABG) or percutaneous coronary intervention (PCI). Unlike in the young, or the middle aged, the elderly have several concurrent comorbid conditions. Further, the elderly are frail and in spite of being afflicted with severe CAD, in view of their age, they are not considered for coronary revascularization procedures. All these affect the outcome of coronary revascularization procedures in the elderly. While some studies $^{5,6}$ have attempted to identify risk factors for mortality and outcome in elderly patients who had undergone CABG, sparse data are available with regard to assessing the predictors for major adverse cardiac events (MACE) following PCI in elderly patients.

The study by Ramakrishnaet $\mathrm{al}^{7}$ featured in the current issue of the journal attempts to study the various predictors of long-term MACE in the elderly patients undergoing elective PCI. The authors ${ }^{7}$ retrospectively reviewed the case records of 355 elderly patients ( 247 males, aged $\geq 70$ years) who underwent elective PCI during the period 2008 to 2018. In the one-year follow-up, MACE had occurred in 24/355 patients and 6/24 patients had died ( 3 had single vessel disease, and the other 3 had multivessel disease). Univariate analysis and multivariable analysis (logistic regression) showed that diabetes mellitus was an independent predictor of occurrence of MACE and death. The authors concluded that PCI was a safe and effective method of coronary revascularization in elderly subjects. They also observed that that presence of risk factors like diabetes mellitus can predict one-year MACE in elderly subjects.

The study ${ }^{7}$ addresses an important question of occurrence of MACE and death following $\mathrm{PCI}$, as $\mathrm{PCI}$ is currently considered the preferred method for revascularization in the elderly. ${ }^{9}$ Importantly, the study provides useful information not only on the short-term outcomes, but also regarding the one-year outcomes in elderly patients who have undergone $\mathrm{PCl}$, an area where published literature is sparse. Given that India is emerging as the diabetes mellitus capital of the world, ${ }^{8}$ the observation documented in the present study regarding the importance of diabetes mellitus is an independent predictor of poor outcome in elderly patients undergoing $\mathrm{PCl}$ and a warning sign.

In this single-center study conducted over a decade, the authors $^{7}$ do not specify the sample size calculation and justification. So, whether the study ${ }^{7}$ is adequately powered to answer the research question is not clear. Further, the analysis of extent of glycemic control among diabetes mellitus patients with and without MACE, and survivors and nonsurvivors, would also have been helpful.

The observations from the present study ${ }^{7}$ suggest that it would be prudent to screen elderly subjects with CAD for diabetes mellitus. The study ${ }^{7}$ also provides data supporting the benefits of instituting PCI early among elderly patients.

\section{Conflict of Interest}

None declared.
Address for correspondence

Y. Sathyanarayana Raju, MD, FICP, Department of General Medicine, Nizam's Institute of Medical Sciences, Panjagutta, Hyderabad, Telangana, 500482, India

(e-mail: raju_ys1197@yahoo.co.in).
DOI https://doi.org/ 10.1055/s-0040-1708568
(C)2020 Women in Cardiology and

Related Sciences

Published online

April 7, 2020
License terms

(오 (1) $\Theta \circledast$ 


\section{References}

1 World Health Organization. Facts about ageing. Available at: http://www.who.int/ageing/about/facts/en/. Accessed on October 10, 2019

2 Population composition. Available at: http://censusindia.gov. in/vital_statistics/SRS_Report/9Chap\%202\%20-\%202011.pdf. Accessed on October 10, 2019

3 Central Statistics Office Ministry of Statistics \& Programme Implementation Government of India Situation analysis of elderly in India. Available at: http://mospi.nic.in/sites/default/files/publication_reports/elderly_in_india.pdf Accessed on October 10, 2019

4 Madhavan MV, Gersh BJ, Alexander KP, Granger CB, Stone GW. Coronary artery disease in patients $\geq 80$ years of age. J Am Coll Cardiol 2018;71(18):2015-2040

5 Dhurandhar V, Saxena A, Parikh R, et al. Comparison of the safety and efficacy of on-pump (oncab) versus off-pump (opcab) coronary artery bypass graft surgery in the elderly: A review of the ANZSCTS Database. Heart Lung Circ 2015;24(12):1225-1232

6 Carmona García P, Mateo E, Hornero F, López Cantero M, Zarragoikoetxea I. Mortality in isolated coronary artery bypass surgery in elderly patients. A retrospective analysis over 14 years. Rev Esp Anestesiol Reanim 2017;64(5):262-272

7 Ramakrishna AS, Rao VSK, Garre I. Gender-wise long-term predictors for major adverse cardiac events following percutaneous coronary intervention in the elderly population. Ind $\mathrm{J}$ Car Dis Wom 2020:5(01):xxx-xxx

8 International Diabetes Federation. International Diabetes Foundation Atlas. 9th ed. Available at: https://diabetesatlas. org/en/ Accessed on December 31, 2019 